\title{
Analisis Susunan Menu Karyawan di Rocky Plaza Hotel Padang
}

\author{
Lise Asnur* dan Dhabita Fudhaila Hadma \\ Jurusan Pariwisata, Fakultas Pariwisata dan Perhotelan, Universitas Negeri Padang \\ "Corresponding author, e-mail: lise.asnur@ fpp.unp.ac.id
}

\begin{abstract}
Abstrak - Artikel ini disusun menggunakan jenis penelitian kuantitatif dengan metode survei bertujuan untuk mengetahui penilaian terhadap susunan menu karyawan di Rocky Plaza Hotel Padang. Populasi dalam penelitian ini berjumlah 118 orang. Penelitian ini melibatkan 91 orang sebagai sampel, yang dipilih menggunakan teknik probability sampling. Data didapatkan dengan berkomunikasi secara tidak langsung menggunakan kuisioner (angket) dengan menggunakan skala likert, angket juga telah diuji validitas serta realibilitasnya terlebih dahulu. Penelitian ini menggunakan analisis deskriptif dalam pengolahan data dan diperoleh gambaran sebaran frekuensi data mencakup nilai maksimal dan minimal, median, mean, standar deviasi serta nilai tingkat pencapaian responden. Berdasarkan penelitian, didapat hasil sebagai berikut: Variabel susunan menu dikategorikan sangat baik dengan persentase $54,9 \%$, Indikator standar porsi dikategorikan sangat baik dengan persentase $60,43 \%$, Indikator standar resep dikategorikan sangat baik dengan persentase $57,14 \%$, Indikator standar bumbu dikategorikan sangat baik dengan persentase $57,14 \%$, Indikator standar kualitas dikategorikan sangat baik dengan persentase $54,94 \%$.
\end{abstract}

Kata Kunci : Analisa susunan menu, Penelitian kuantitatif, Rocky Plaza Hotel

\begin{abstract}
This article was prepared using a quantitative research type with a survey method which aims to determine the assessment of the menu arrangement of employees at Rocky Plaza Hotel Padang. The population in this study amounted to 118 people. This study involved 91 people as a sample, who were selected using probability sampling techniques. Data obtained by communicating indirectly using a questionnaire (questionnaire) using a Likert scale, the questionnaire has also been tested for validity and reliability first. This study used descriptive analysis in data processing and obtained a description of the distribution of data frequencies including values maximum and minimum, median, mean, standard deviation and the value of the level of achievement of the respondents. Based on the research, the following results were obtained: The menu arrangement variable was categorized as very good with a percentage of $54.9 \%$, the standard indicator portion was categorized as very good with a percentage of $60.43 \%$, the standard recipe indicator was categorized as very good with a percentage of $57.14 \%$, the standard indicator of spices categorized as very good with a percentage of $57.14 \%$, indicators of quality standards are categorized as very good with a percentage of $54.94 \%$.
\end{abstract}

Keywords : Menu arrangement analysis, Quantitative research,Rocky Plaza Hotel

\section{Pendahuluan}

Kota Padang adalah pusat pemerintahan Provinsi Sumatera Barat yang memiiliki banyak potensi wisata.[1] Salah satu kebutuhan wisatawan ketika mengunjungi suatu lokasi wisata yaitu akomodasi. Hotel merupakan jenis akomodasi yang cukup digemari wisatawan. Salah satu hotel berbintang yang ada di Kota Padang yaitu Rocky Plaza Hotel Padang berada di Jl. Permindo Kel No.40, Kp. Jao, Kec. Padang Bar., Kota Padang, Sumatera Barat. Lokasinya ini merupakan lokasi yang strategis karena berada di pusat kota, dekat dengan pusat perbelanjaan dan 
bioskop serta lokasi wisata Pantai Padang. Hotel ini memiliki 171 kamar dan 118 orang karyawan yang terbagi dalam 10 departemen termasuk direksi. Sebuah hotel biasanya menyediakan makan minimal satu kali sehari. Asupan makanan yang bergizi sangat penting bagi pekerja atau karyawan terutama pada karyawan yang melibatkan banyak aktivitas fisik. Umumnya, hotel memiliki kantin karyawan yang menyediakan makanan dan minuman bagi karyawan dengan susunan menu yang bervariasi sesuai dengan ketetapan hotel.

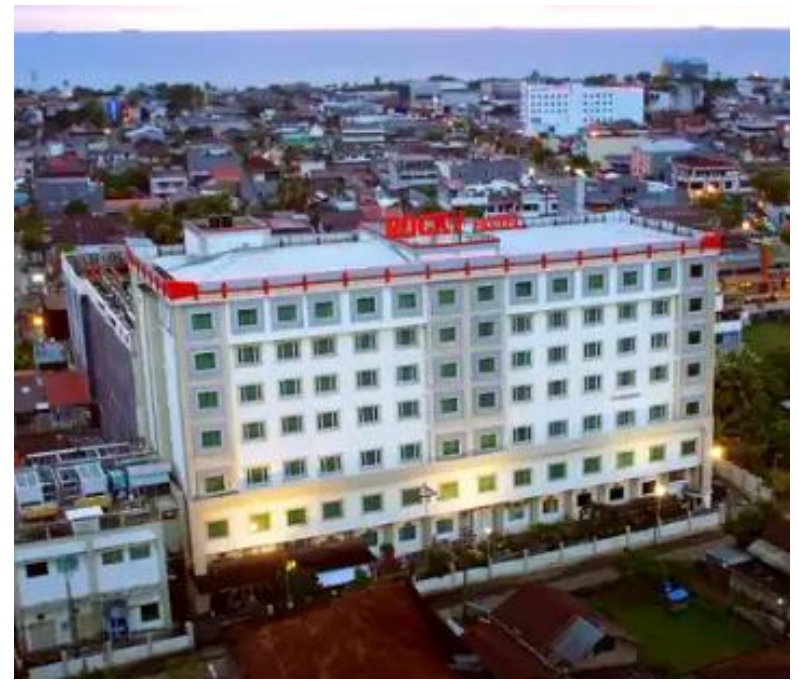

Gambar 1. Rocky Plaza Hotel

Menurut Bakri [2] pengaturan beberapa jenis hidangan atau masakan yang dihidangkan atau ditampilkan untuk seorang atau sekelompok orang untuk sekali makan, yang dapat berupa susunan hidangan sarapan pagi, hidangan makan siang atau hidangan makan malam termasuk snack disebut dengan menu

Kemudian yang disebut dengan penyelenggaraan makanan institusi dan industri adalah "program terpadu yang terdiri atas perencanaan, pengadaan, penyimpanan, pengelolaan bahan makanan, dan penghidangan makanan dalam skala besar (massal) serta pengadaan peralatan dan cara yang diperlukan untuk mencapai tujuan yang dikoordinasikan secara penuh dengan menggunakan lembaga kerja sedikit mungkin, tetapi harus mengutamakan kepuasan pelayanan, kualitas yang maksimal dan pengontrolan biaya yang baik pada sebuah institusi atau industri" [3]

Penyusunan menu dengan perencanaan yang baik dapat memberikan beberapa kegunaan yaitu, menu mengandung zat gizi yang dibutuhkan oleh tubuh, menu mempunyai variasi dan kombinasi yang tepat sehingga dapat menghindari kebosanan, pengadaan menu sesuai dengan kondisi keuangan atau biaya yang tersedia, hemat waktu dan tenaga cateriing, dan dapat menjadi alat pendidikan gizi karena menu yang baik akan mengajarkan pola makan yang baik.

Beberapa penelitian tentang menu dan hidangan telah dilakukan oleh peneliti lain diantaranya hidangan desert [4] main dish [5]. Menu juga memiliki pengaruh pada pengunjung restoran yang ada pada sebuah hotel [6]. Pemberian makanan dan menu makan siang juga memiliki pengaruh terhadap produktvitas kerja karyawan [7].

Susunan menu yang baik diperlukan bagi sebuah perusahaan agar makanan yang diberikan memiliki standar dan tidak membosankan bagi karyawan. [8] Selain itu, melalui susunan menu sebuah perusahaan dapat menentukan anggaran biaya yang akan dikeluarkan untuk menyediakan makanan bagi karyawannya. Susunan menu biasanya dirancang oleh pihak manajemen dan memiliki pergantian sesuai dengan kebijakan hotel dan anggaran yang telah ditetapkan. Menu untuk karyawan di Rocky Plaza Hotel Padang diproduksi oleh bagian kitchen hotel.

\section{METODE}

Penelitian ini menggunanakan metode penelitian kuantitatif dengan metode survei. Metode ini untuk mendapatkan sebuah pengetahuan atau informasi menggunakan data atau angka sebagai alat penganalisa [9].

Populasi dalam penelitian ini berjumlah 118 orang. Sampel dalam penelitian ini sebanyak 91 orang yang dipilih dengan menggunakan teknik probability sampling. Teknik pengumpulan data dilakukan dengan komunikasi tidak langsung melalui kuisioner (angket) dengan menggunakan skala likert yang telah diuji validitas serta realibilitasnya terlebuh dahulu. Beberapa item pertanyaan yang disusun di dalam angket.

Penelitian ini menggunakan analisis deskriptif dalam pengolahan data dan diperoleh gambaran distribusi frekuensi data yang mencakup nilai dan minimal, mean, median, standar deviasi dan tingkat pencapaian responden.

\section{HASIL DAN PEMbahaSAN}

Angket yang sudah diisi kemudian ditabulasi dan diolah untuk selanjutnya dideskripsikan dengan bantuan software statistik. Berikut adalah penjabaran dari hasil penelitian dan juga pembahasannya. 


\section{A. Hasil Penelitian}

Data mengenai analisis susunan menu karyawan di Rocky Plaza Hotel Padang dapat dilihat pada tabel 1. Berdasarkan distribusi skor di tabel 1, didapat skor rata - rata (mean) sebesar 120,75 , skor tengah (median) sebesar 124,00, skor yang sering muncul (mode) sebesar 124, smpangan baku (std. deviation) sebesar 20,315, variance sebesar 412,680, range sebesar 98 , nilai minimum sebesar 57 dan nilai maksimal sebesar 155, totalnya sebesar 10988 .

Tabel 1. Data Deskriptif Susunan Menu Karyawan Di Rocky Plaza Hotel Padang

\begin{tabular}{|ll|r|}
\hline N & Valid & 91 \\
& Missing & 0 \\
Mean & & 120.75 \\
Std. Error of Mean & 2.130 \\
Median & 124.00 \\
Mode & 124 \\
Std. Deviation & & 20.315 \\
Variance & & 412.680 \\
Range & & 98 \\
Minimum & & 57 \\
Maximum & & 155 \\
Sum & & 10988 \\
& 25 & 110.00 \\
Percentiles & 50 & 124.00 \\
& 75 & 135.00 \\
\hline
\end{tabular}

Sumber : Data Primer, 2020 (Diolah)

Histogram kurva normal sebaran data penelitian dapat dilihat pada Gambar 2.

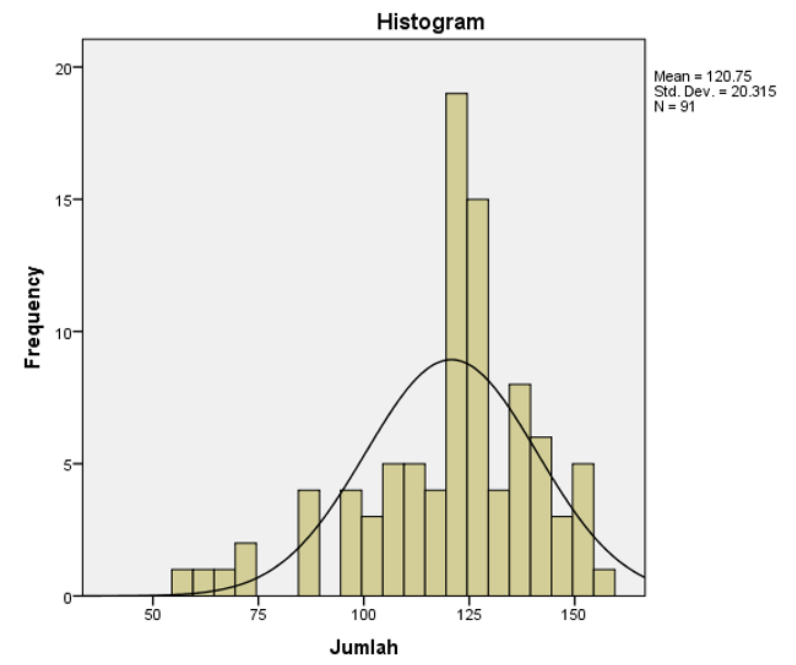

Sumber: Data Primer, 2020 (Diolah)

Gambar 2. Histogram Kurva Normal Sebaran Variabel Analisis Susunan Menu Karyawan Di Rocky Plaza Hotel Padang

Histogram kurva normal sebaran data mengenai tercapainya variabel susunan menu karyawan menunjukkan bentuk melengkung sempurna yang berarti sebaran data normal atau merata. Setelah diperoleh perhitungan statistik, brikut disajikan klasifikasi skor pencapaian responden untuk menggambarkan kategori penilaian hasil penelitian pada tabel 2 :

Tabel 2. Distribusi Frekuensi Data Susunan Menu Karyawan

\begin{tabular}{|l|l|l|l|}
\hline Kategori & $\begin{array}{l}\text { Rentang } \\
\text { Skor }\end{array}$ & Frekuensi & $\begin{array}{l}\text { Persentase } \\
(\%)\end{array}$ \\
\hline $\begin{array}{l}\text { Sangat } \\
\text { Baik }\end{array}$ & $\geq 124,05$ & 50 & $54,9 \%$ \\
\hline Baik & $\begin{array}{l}103,33 \leq \\
124,05\end{array}$ & 27 & $29,67 \%$ \\
\hline Cukup & $\begin{array}{l}82,67 \leq \\
103,33\end{array}$ & 9 & $9,89 \%$ \\
\hline Buruk & $\begin{array}{l}61,95 \leq \\
82,67\end{array}$ & 4 & $4,39 \%$ \\
\hline $\begin{array}{l}\text { Sangat } \\
\text { Buruk }\end{array}$ & $<61,95$ & 1 & $1,09 \%$ \\
\hline TOTAL & & 91 & $100 \%$ \\
\hline
\end{tabular}

Sumber : Data Primer, 2020 (Diolah)

Berdasarkan tabel 2 diatas, dapat dilihat bahwa sebanyak 54,9\% responden memberi respon sangat baik terhadap susunan menu karyawan yang disediakan, 29,67\% memberi respon baik, $9,89 \%$ memberi respon cukup, 4,39\% responden memberi respon buruk, dan $1,09 \%$ responden memberikan respon sangat buruk terhadap susunan menu karyawan di Rocky Plaza Hotel Padang.

Hasil penelitian berdasarkan indikator indikator susunan menu adalah sebagai berikut 
1. Indikator Standar Porsi

Data yang diperoleh dari 91 orang responden yang terdiri dari 6 pernyataan mengenai indikator standar porsi dapat dilihat pada tabel 3.

Berdasakan distribusi skor pada tabel 3 tersebut, didapat skor rata - rata (mean) sbesar 23,22, skor tengah (median) sebesar 24,00, skor yang sering muncul (mode) sebesar 24, simpangan baku (std. deviation) sebesar 4,341, variance 18,840 , range 20 , nilai minimum 10 dan nilai maksimum 30. Total sebesar 2113. Histogram kurva normal sebaran data penelitian dapat dilihat pada gambar 3 .

Histogram kurva normal sebaran data mengenai tercapainya indikator standar porsi menunjukan bentuk melengkung sempurna yang berarti sebaran data normal atau merata. Setelah diperoleh perhitungan statistik, Tabel 4 menunjukkan klasifikasi skor pencapaian skor responden

Tabel 3. Data Deskriptif

Indikator Standar Porsi

jumlah_x1

\begin{tabular}{|c|c|c|}
\hline \multirow{2}{*}{ N } & Valid & 91 \\
\hline & Missing & 0 \\
\hline \multicolumn{2}{|l|}{ Mean } & 23.22 \\
\hline \multicolumn{2}{|c|}{ Std. Error of Mean } & .455 \\
\hline \multicolumn{2}{|l|}{ Median } & 24.00 \\
\hline \multicolumn{2}{|l|}{ Mode } & 24 \\
\hline \multicolumn{2}{|c|}{ Std. Deviation } & 4.341 \\
\hline \multicolumn{2}{|l|}{ Variance } & 18.840 \\
\hline \multicolumn{2}{|l|}{ Range } & 20 \\
\hline \multicolumn{2}{|l|}{ Minimum } & 10 \\
\hline \multicolumn{2}{|l|}{ Maximum } & 30 \\
\hline \multicolumn{2}{|l|}{ Sum } & 2113 \\
\hline & 25 & 21.00 \\
\hline \multirow[t]{2}{*}{ Percentiles } & 50 & 24.00 \\
\hline & 75 & 25.00 \\
\hline
\end{tabular}

Sumber: Data Primer, 2020 (Diolah)

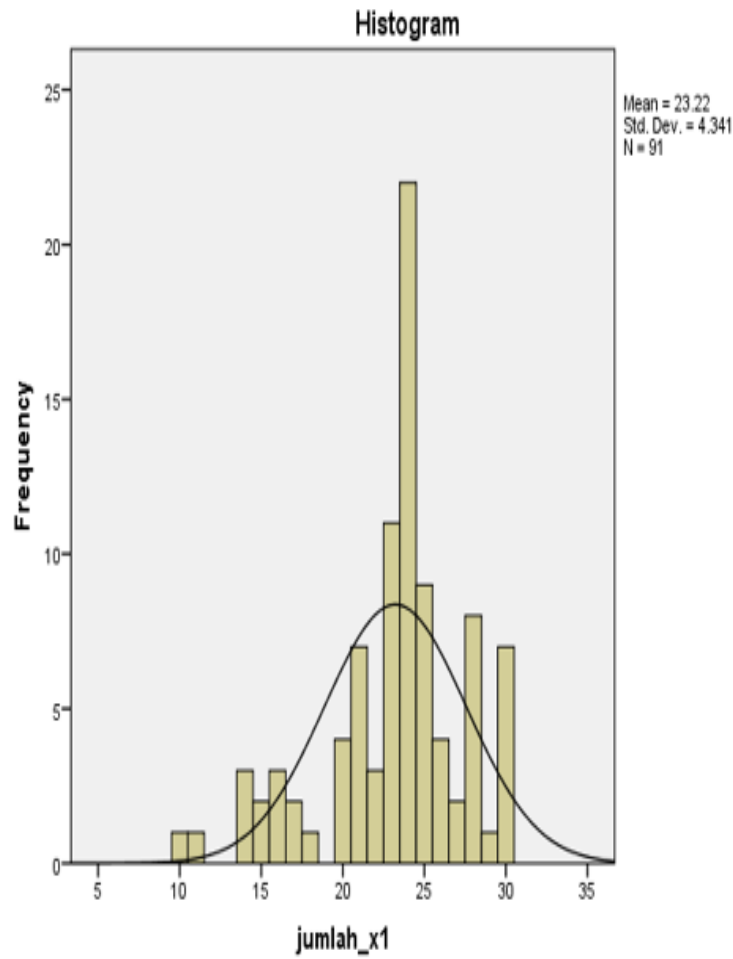

Gambar 3. Histogram Kurva Normal Sebaran Indikator Standar Porsi

Tabel 4 menjelaskan bahwa pada indikator standar porsi sebanyak $60,43 \%$ responden memberikan respon sangat baik terhadap indikator standar porsi, 25,27\% responden memberikan respon yang baik, 6,59\% responden memberikan respon cukup, 5,49\% responden memberikan respon buruk, dan 2,19\% responden memberikan respon sangat buruk terhadap indikator standar porsi pada usunan menu karyawan di Rocky Plaza Hotel Padang.

Tabel 4. Distribusi Frekuensi Data Indikator Standar Porsi

\begin{tabular}{|l|l|l|l|}
\hline Kategori & $\begin{array}{l}\text { Rentang } \\
\text { Skor }\end{array}$ & Frekuensi & $\begin{array}{l}\text { Persentase } \\
(\%)\end{array}$ \\
\hline $\begin{array}{l}\text { Sangat } \\
\text { Baik }\end{array}$ & $\geq 24$ & 55 & $60,43 \%$ \\
\hline Baik & $20 \leq 24$ & 23 & $25,27 \%$ \\
\hline Cukup & $16 \leq 20$ & 6 & $6,59 \%$ \\
\hline Buruk & $12 \leq 16$ & 5 & $5,49 \%$ \\
\hline $\begin{array}{l}\text { Sangat } \\
\text { Buruk }\end{array}$ & $<12$ & 2 & $2,19 \%$ \\
\hline TOTAL & & 91 & $100 \%$ \\
\hline
\end{tabular}

Sumber: Data Primer, 2020 (Diolah) 
2. Indikator Standar Resep

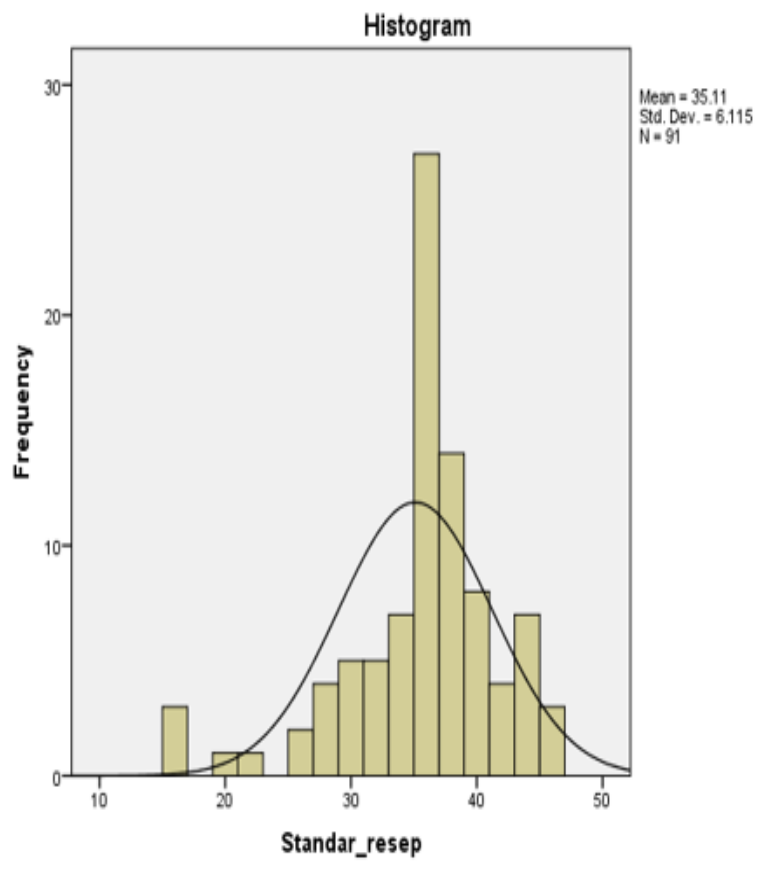

Gambar 4. Histogram Kurva Normal Sebaran Indikator Standar Resep

Data yang diperoleh dari 91 responden dengan 9 pernyataan mengenai indikator standar resep dapat dilihat pada tabel 5

Berdasarkan tabel 5, didapat data mean 35,11, skor tengan (median) 36,00, skor yang sering muncul (mode) 36, simpangan baku (std.deviation) 6,115, variance 37,388 , range 29 , nilai minimum 16 dan nilai maksimum 45 , total 3195. Histogram kurva normal seperti dapat dilihat di Gambar 4

Tabel 5. Data Deskriptif Indikator Standar Resep

Statistics

Standar resep

\begin{tabular}{|l|r|}
\hline N & Valid \\
Mean & Missing \\
Std. Error of Mean & 0 \\
Median & 35.11 \\
Mode & .641 \\
Std. Deviation & 36.00 \\
Variance & 36 \\
Range & 6.115 \\
Minimum & 37.388 \\
Maximum & 29 \\
& 16 \\
\hline
\end{tabular}

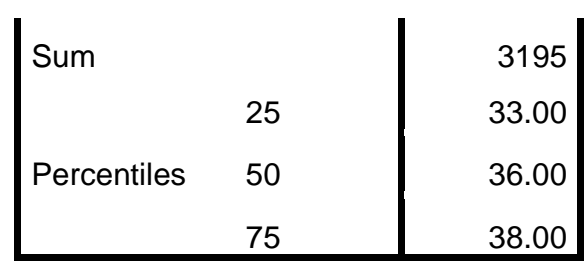

Sumber: Data Primer, 2020 (Diolah)

Histogram kurva normal menunjukkan bentuk melengkung sempurna yang berarti sebaran data normal atau merata.Setelah diperoleh perhitungan statistik, berikut skor pencapaian responden untuk menggambarkan kategori penilaian hasil penelitian :

Tabel 6. Distribusi Frekuensi Data Indikator Standar Resep

\begin{tabular}{|l|l|l|l|}
\hline Kategori & $\begin{array}{l}\text { Rentang } \\
\text { Skor }\end{array}$ & $\begin{array}{l}\text { Frekuen } \\
\text { si }\end{array}$ & $\begin{array}{l}\text { Persentase } \\
(\%)\end{array}$ \\
\hline $\begin{array}{l}\text { Sangat } \\
\text { Baik }\end{array}$ & $\geq 36$ & 52 & $57,14 \%$ \\
\hline Baik & $30 \leq 36$ & 26 & $28,57 \%$ \\
\hline Cukup & $24 \leq 30$ & 8 & $8,79 \%$ \\
\hline Buruk & $18 \leq 24$ & 2 & $2,19 \%$ \\
\hline $\begin{array}{l}\text { Sangat } \\
\text { Buruk }\end{array}$ & $<18$ & 3 & $3,29 \%$ \\
\hline TOTAL & & 91 & $100 \%$ \\
\hline
\end{tabular}

Sumber: Data Primer, 2020 (Diolah)

Tabel 6 menjelaskan bahwa pada indikator standar resep sebanyak $57,14 \%$ responden memberikan respon pada kategori sangat baik, $28,57 \%$ responden memberikan respon baik, $8,79 \%$ memberikan respon cukup, 2,19\% responden memberikan respon buruk, dan 3,29\% responden memberikan respon sangat buruk terhadap indikator standar resep pada susunan menu karyawan di Rocky Plaza Hotel Padang.

\section{Indikator Standar Bumbu}

Data yang diperoleh dari 91 responden terdiri 8 pernyataan mengenai indikator standar bumbu dapat dilihat pada tabel 7

Tabel 7. Data Deskriptif Indikator Standar Bumbu

Standar_bumbu

\begin{tabular}{|c|c|c|}
\hline \multirow{2}{*}{$\mathrm{N}$} & Valid & 91 \\
\hline & Missing & 0 \\
\hline \multicolumn{2}{|c|}{ Mean } & 31.38 \\
\hline \multicolumn{2}{|c|}{ Std. Error of Mean } & .558 \\
\hline \multicolumn{2}{|c|}{ Median } & 32.00 \\
\hline \multicolumn{2}{|c|}{ Mode } & 33 \\
\hline \multicolumn{2}{|c|}{ Std. Deviation } & 5.318 \\
\hline
\end{tabular}




\begin{tabular}{|c|c|c|}
\hline \multicolumn{2}{|l|}{ Variance } & 28.284 \\
\hline \multicolumn{2}{|l|}{ Range } & 25 \\
\hline \multicolumn{2}{|l|}{ Minimum } & 15 \\
\hline \multicolumn{2}{|l|}{ Maximum } & 40 \\
\hline \multirow[t]{2}{*}{ Sum } & & 2856 \\
\hline & 25 & 29.00 \\
\hline \multirow[t]{2}{*}{ Percentiles } & 50 & 32.00 \\
\hline & 75 & 35.00 \\
\hline
\end{tabular}

Sumber: Data Primer, 2020 (Diolah)

Berdasarkan tabel 7 dapat diketahui mean 31,38 , median 32,00, mode 33, standar deviasi 5,318 , variance 28,284 , range 25 , nilai minimum 15, nilai maksimum 40 dan jumlah 2856. Histogram kurva normal sebaran data penelitian dapat dilihat pada gambar 5

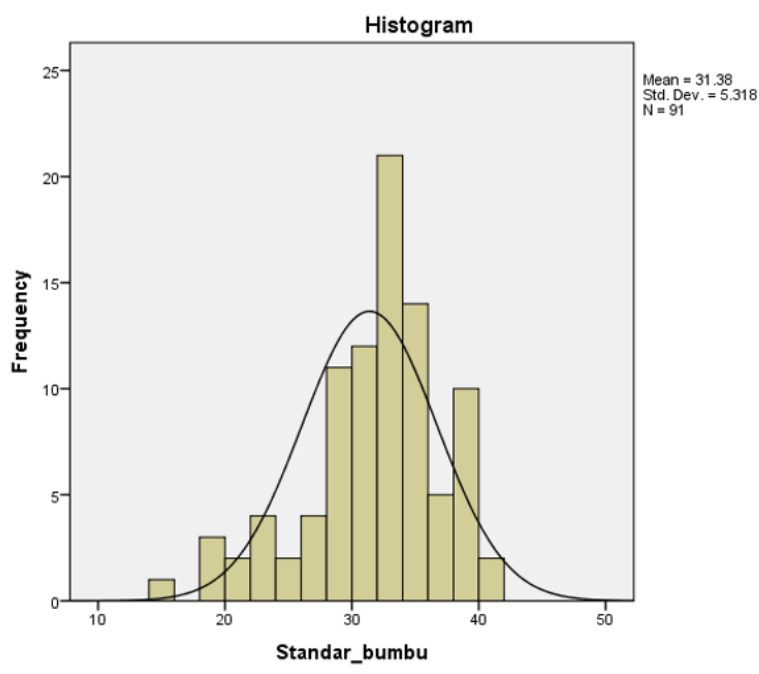

Gambar 5. Histogram Kurva Normal

Sebaran Indikator Standar Bumbu

Histogram kurva normal menunjukkan bentuk melengkung sempurna yang berarti sebaran data normal atau merata. Tabel 7 Berikut disajikan klasifikasi skor pencapaian responden untuk menggambarkan hasil penelitian

Tabel 7. Distribusi Frekuensi Data Indikator Standar Bumbu

\begin{tabular}{|l|l|l|l|}
\hline Kategori & $\begin{array}{l}\text { Rentang } \\
\text { Skor }\end{array}$ & Frekuensi & $\begin{array}{l}\text { Persentase } \\
(\%)\end{array}$ \\
\hline $\begin{array}{l}\text { Sangat } \\
\text { Baik }\end{array}$ & $\geq 31,95$ & 52 & $57,14 \%$ \\
\hline Baik & $\begin{array}{l}26,65 \leq \\
31,95\end{array}$ & 25 & $27,47 \%$ \\
\hline Cukup & $\begin{array}{l}21,35 \leq \\
26,65\end{array}$ & 9 & $9,89 \%$ \\
\hline Buruk & $\begin{array}{l}16,05 \leq \\
21,35\end{array}$ & 4 & $4,39 \%$ \\
\hline Sangat & $<16,05$ & 1 & $1,09 \%$ \\
\hline
\end{tabular}

\begin{tabular}{|l|l|l|l|}
\hline Buruk & & & \\
\hline TOTAL & & 91 & $100 \%$ \\
\hline
\end{tabular}

Sumber: Data Primer, 2020 (Diolah)

Tabel 7 diatas menjelaskan bahwa sebanyak $57,14 \%$ pada kategori sangat baik, $27,47 \%$ baik, $9,89 \%$ cukup, $4,39 \%$ buruk, dan $1,09 \%$ sangat buruk.

\section{Indikator Standar Kualitas}

Data yang diperoleh dari 91 responden terdiri dari 8 pernyataan mengenai indikator standar kualitas dapat dilihat pada tabel 8

Tabel 8. Data Deskriptif Indikator Standar Kualitas

\section{Statistics}

\begin{tabular}{|lr|r|}
\hline Standar_Kualitas & \multicolumn{1}{c|}{ Valid } & 91 \\
Mean & Missing & 0 \\
Std. Error of Mean & 31.03 \\
Median & .538 \\
Mode & 32.00 \\
Std. Deviation & & 32 \\
Variance & & 5.130 \\
Range & & 26.321 \\
Minimum & & 27 \\
Maximum & & 13 \\
Sum & & 40 \\
& 25 & 2824 \\
Percentiles & 50 & 28.00 \\
& 75 & 32.00 \\
\hline
\end{tabular}

Sumber: Data Primer, 2020 (Diolah)

Pada tabel 8 diketahui mean 31,03, median 32,00 , mode 32, standar deviasi 5,130, variance 26,321 , range 27 , nilai minimum 13 , nilai maksimum 40, dan jumlah 2824. Histogram kurva normal sebaran data penelititian dapat dilihat pada gambar 6 


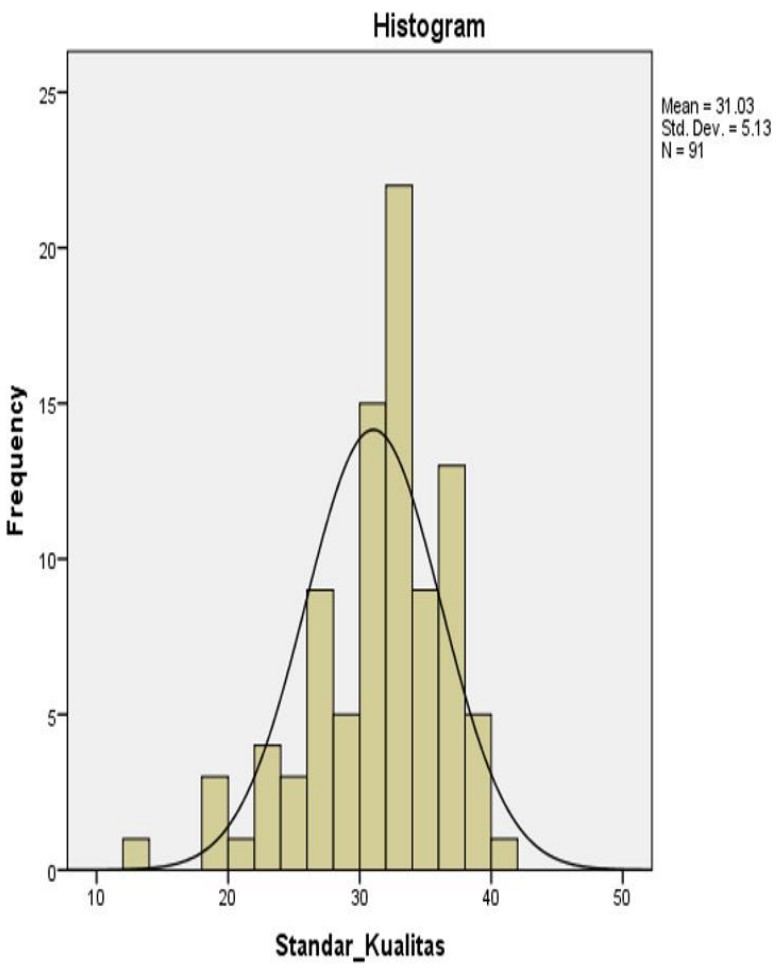

Gambar 6. Histogram Kurva Normal Sebaran Indikator Standar Kualitas

Histogram kurva diatas menunjukkan bentuk melengkung sempurna yang berarti sebaran data normal atau merata. Setelah diperoleh perhitungan statistik diatas, berikut disajikan klasifikasi skor pencapain responden untuk menggambarkan kategori penilaian hasil penelitian :

Tabel 9. Distribusi Frekuensi Data Indikator Standar Kualitas

\begin{tabular}{|l|l|l|l|}
\hline Kategori & $\begin{array}{l}\text { Rentang } \\
\text { Skor }\end{array}$ & Frekuensi & $\begin{array}{l}\text { Persentase } \\
(\%)\end{array}$ \\
\hline $\begin{array}{l}\text { Sangat } \\
\text { Baik }\end{array}$ & $\geq 124,05$ & 50 & $54,9 \%$ \\
\hline Baik & $\begin{array}{l}103,33 \leq \\
124,05\end{array}$ & 27 & $29,67 \%$ \\
\hline Cukup & $\begin{array}{l}82,67 \leq \\
103,33\end{array}$ & 9 & $9,89 \%$ \\
\hline Buruk & $\begin{array}{l}61,95 \leq \\
82,67\end{array}$ & 4 & $4,39 \%$ \\
\hline $\begin{array}{l}\text { Sangat } \\
\text { Buruk }\end{array}$ & $<61,95$ & 1 & $1,09 \%$ \\
\hline TOTAL & & 91 & $100 \%$ \\
\hline
\end{tabular}

Sumber : Data Primer, 2020 (Diolah)

Berdasarkan tabel 9 diketahui bahwa 54,9\% responden memberikan respon sangat baik, $29,67 \%$ responden memberikan respon baik, 9,89\% memberikan respon cukup, 4,39\% responden memberikan respon buruk, dan 1,09\% responden memberikan responsangat buruk terhadap standar kualitas pada susunan menu karyawan di Rocky Plaa Hotel Padang.

\section{B. Pembahasan}

Berdasarkan penelitian yang telah dilakukan tentang susunan menu karyawan di Rocky Plaza Hotel Padang, dapat dijelaskan dari 91 orang responden disimpulkan bahwa variabel susunan menu karyawan digolongkan pada kategori sangat baik dengan persentase sebesar $54,9 \%$. Susunan menu terdiri dari beberapa indikator, yaitu stndar porsi, standar resep, standar bumbu, dan standar kualiitas. Pada masing - masing indikator tersebut, hasil penelitian tergolong sangat baik.

Menurut Bakri [2], tujuan penyelenggaraan makanan bagi tenaga kerja adalah untuk mencapai tingkat kesehatan dan stamina pekerja yang sebaik - baiknya agar dapat diciptakan suasana kerja yang memungkinkan tercapainya produktivitas kerja yang maksimal. Pada penelitian ini, pendapat karyawan mengenai susunan menu makanan yang disajikan di kantin karyawan sudah tergolong sangat baik baik secara keseluruhan maupun. Untuk itu, pihak hotel perlu mempertahankan susunan menu berdasarkan indikator standar porsi, standar resep, standar bumbu, dan standar kualitas yang diberikan untuk karyawan agar karyawan merasa puas dan kinerja pun semakin meningkat.

\section{KESIMPULAN}

Susunan menu karyawan di Rocky Plaza Hotel Padang secara umum tergolong sangat baik dengan persentase $54,9 \%$, baik $29,67 \%$, cukup $9,89 \%$, buruk $4,39 \%$, dan sangat buruk $1,09 \%$. Jadi, dapat disimpulkan bahwa susunan menu karyawan di Rocky Plaza Hotel Padang tergolong sangat baik.

\section{DAfTAR PUStaka}

[1] "Kota Padang," Wikipedia bahasa Indonesia, ensiklopedia bebas. Aug. 28, 2020, Accessed: Oct. 05, 2019. [Online]. Available: https://id.wikipedia.org/w/index.php?title=Kota_P adang\&oldid=17344039.

[2] B. Bakri and A. Intiyati, "Sistem Penyelenggara Makanan Institusi," 2019.

[3] D. Wulansari, "Menu Engineering (Studi Deskriptif Tentang Pemanfaatan Menu Engineering Dalam Penyusunan Menu Makanan Di Tulipe Restaurant Golden Tulip Legacy Hotel Surabaya)," PhD Thesis, UNIVERSITAS AIRLANGGA, 2019. 
[4] N. Nur Quraniah, "Pelayanan Hidangan Dessert pada Menu Ala Carte di Rahisa Restaurant Sahira Butik Hotel," 2020.

[5] T. Febianti Iriadi, "Pelayanan Hidangan Main Dish pada Menu Ala Carte di Rahisa Restaurant Sahira Butik Hotel Paledang Bogor,” 2020.

[6] D. D. Ismoyo, "Pengaruh Variasi Menu dan Cita Rasa Makanan Buffet Dinner Terhadap Kepuasan Tamu Restoran Gris di Crowne Plaza Semarang," Gemawisata J. Ilm. Pariwisata, vol. 13, no. 1, 2017.

[7] W. Astuti, "Pengaruh Pemberian Makanan Tambahan Dalam Menu Makan Siang Terhadap Produktivitas Kerja Karyawan Unit Filling PT. Indo Accidatama Kemiri Kebakramat Karanganyar,"2012

[8] M. Rotua and R. Siregar, "Manajemen Sistem Penyelenggaraan Makanan Institusi Dasar,” 2019.
[9] M. Kasiram, Metodologi penelitian: Kualitatifkuantitatif. Uin-Maliki Press, 2010.

\section{Biodata Penulis}

Lise Asnur, M.Pd, Lahir di Pekanbaru pada tanggal 22 Agustus 1966. Sarjana Pendidikan di Jurusan Tata Boga FT UNIMED 2003. Tahun 2012 memperoleh gelar Magister Pendidikan di jurusan Teknologi Pendidikan Program Pascasarjana UNP dengan bidang konsentrasi Pendidikan Kejuruan. Staf pengajar di jurusan Pariwisata FPP UNP sejak tahun 2016 - sekarang.

Dhabita Fudhaila Hadma, Lahir di Bukittinggi tanggal 4 Juni 1998, Saat ini tengah menempuh pendidikan di jurusan pariwisata program studi D4 Manajemen Perhotelan,Universitas Negeri Padang semester akhir. Penelitian ini ditujukan sebagai salah satu syarat memperoleh gelar sarjana Sains Terapan ( S.ST). 